Kansas State University Libraries

New Prairie Press

\title{
HYDROLOGICAL NORMALIZATION OF NUTRIENT DELIVERIES FROM AGRICULTURAL CATCHMENTS
}

Per Stalnacke

Anders Grimvall

Follow this and additional works at: https://newprairiepress.org/agstatconference

Part of the Agriculture Commons, and the Applied Statistics Commons

\section{(c) (1) $\Theta(9$}

This work is licensed under a Creative Commons Attribution-Noncommercial-No Derivative Works 4.0 License.

\section{Recommended Citation}

Stalnacke, Per and Grimvall, Anders (1999). "HYDROLOGICAL NORMALIZATION OF NUTRIENT DELIVERIES FROM AGRICULTURAL CATCHMENTS," Conference on Applied Statistics in Agriculture. https://doi.org/10.4148/2475-7772.1266

This is brought to you for free and open access by the Conferences at New Prairie Press. It has been accepted for inclusion in Conference on Applied Statistics in Agriculture by an authorized administrator of New Prairie Press. For more information, please contact cads@k-state.edu. 


\title{
HYDROLOGICAL NORMALIZATION OF NUTRIENT DELIVERIES FROM AGRICULTURAL CATCHMENTS
}

\author{
Per Stålnacke \\ Jordforsk - Centre for Soil and Environmental Research, NO-1432 As, Norway \\ Anders Grimvall \\ Department of Mathematics, Linköping University, SE-581 83 Linköping, Sweden
}

\begin{abstract}
Nutrient deliveries from agricultural catchments are strongly influenced by natural fluctuations in water discharge. Hydrological normalization of such data may therefore facilitate estimation of human impact on the environment. In the present study, we compared conventional statistical normalization techniques with a recently proposed, semi-parametric regression technique, which can accommodate time-dependent relationships between nutrient deliveries and water discharge. Case studies of agricultural catchments in Sweden and Norway demonstrated that all of the tested normalization techniques were able to remove a substantial fraction of the interannual variation in nitrogen deliveries, whereas normalization of phosphorus loads was problematic. Semi-parametric regression models were found to be useful when temporal trends were present in the analyzed time series.
\end{abstract}

Key words: normalization, trend analysis, semi-parametric regression, agricultural runoff, hydrology, nutrients

\section{Introduction}

Detection of long-term trends in time series of water quality data is one of the major objectives of many monitoring programs. Therefore, substantial efforts have been made to assess the power of various trend tests and to investigate the implications of missing data, outliers, seasonality and serial correlation (e.g. Helsel \& Hirsch, 1992; Esterby, 1996). Furthermore, several investigators have claimed that non-parametric tests based on Kendall's $\tau$ are particularly useful to detect monotone trends in environmental quality (Hirsch et al., 1982; Hirsch and Slack, 1984; Loftis et al., 1991). In the present study, we investigate how trend detection can be facilitated by first removing a substantial fraction of the natural fluctuations in the time series of observed data. In particular, we determine how time series of nutrient delivery data can be decomposed into two components: a random component that picks up the impact of natural fluctuations in water discharge, and a hydrologically normalized component that may be regarded as an estimate of human impact on water quality.

If detailed information on land-use and hydrogeological characteristics is available, mechanistic or process-oriented models, such as SOIL-N (Johnsson et al., 1987), DAISY (Hansen et al., 1991) and AGNPS (Young et al., 1989), can provide powerful tools for flownormalization. If such information is less detailed, or the study area contains a variety of landscape elements, a purely statistical approach is often more suitable. Behrendt (1997) proposed a simple partitioning of all data into subsets representing different flow regimes. We 
focus on procedures in which nutrient deliveries are regressed on water discharge. Specifically, we describe and evaluate:

- conventional flow-normalization techniques involving time-independent relationships between nutrient delivery and discharge;

- semi-parametric flow-normalization techniques in which the relationships between nutrient delivery and discharge are permitted to vary smoothly over time.

The empirical data sets represent selected agricultural catchments in Norway and Sweden (see chapter 3).

\section{Methods}

\section{A. Techniques involving time-independent relationships between nutrient export and water discharge}

If the concentration of the substance under consideration is fairly independent of both the runoff and the season, a very simple normalization of annual exports (loads) can be achieved by computing

$$
\widetilde{L}_{i}=L_{i} \frac{\bar{q}}{q_{i}}
$$

where $L_{i}$ denotes the total export the $i$ th year, $q_{i}$ is the total runoff the same year and $\bar{q}$ the mean annual runoff for the entire study period.

Linear relationships between seasonal values of substance loads and runoff can be accommodated by using regression equations of the form

$$
L_{i j}=\alpha+\beta q_{i j}+\varepsilon_{i j}, \quad i=1,2, \ldots, n, \quad j=1,2, \ldots, m,
$$

where $L_{i j}$ denotes the load during the $j$ th season (e.g. the $j$ th month or fortnight period) of the $i$ th year, $q_{i j}$ is the runoff during the same period, $\varepsilon_{i j}$ is a random error term, and $\alpha$ (intercept) and $\beta$ (slope) are model parameters. Flow-normalized seasonal loads can then be calculated according to:

$$
\widetilde{L}_{i j}=L_{i j}-\left(q_{i j}-\bar{q}_{. j}\right) \hat{\beta}
$$

where $\hat{\beta}$ denotes the estimated slope parameter and $\bar{q}_{. j}$ is the average runoff during the $j$ th season. Furthermore, annual flow-normalized loads can be obtained by straightforward aggregation of the seasonal values according to:

$$
\widetilde{L}_{i}=\sum_{j} \widetilde{L}_{i j}=L_{i}-\left(q_{i}-\bar{q}\right) \hat{\beta}
$$

If the relationship between nutrient load and runoff exhibits seasonality, the linear regression model A2 can be extended and generalized to:

$$
L_{i j}=\alpha_{j}+\beta_{j} q_{i j}+\varepsilon_{i j}, \quad i=1,2, \ldots, n, \quad j=1,2, \ldots, m,
$$

where $\alpha_{j}$ and $\beta_{j}, j=1,2, \ldots, m$, are model parameters. In such cases, flow-normalized values can be calculated according to the following:

$$
\tilde{L}_{i j}=L_{i j}-\left(q_{i j}-\bar{q}_{. j}\right) \hat{\beta}_{j}
$$


where $\hat{\beta}_{j}$ denotes the estimated slope parameter for the $j$ th season. Yet other normalization formulas can easily be derived by using multivariate regression models instead of univariate models.

\section{B. Techniques involving time-dependent relationships between nutrient export and water discharge}

If time series of nutrient loads exhibit a pronounced temporal trend, it is likely that the relationships between substance load and runoff also change over time. Hence, it would be desirable to introduce time-varying parameters in the models described above. However, if the intercept and slope parameters in A3 were allowed to vary freely with the year of observation, the number of parameters to be estimated would exceed the number of observations. Using conventional statistical procedures, we would either split the data set into two or more subsets representing different time intervals and analyze load and runoff relationships separately (further referred as method B1) or introduce some kind of linear or other parametric restrictions on the model parameters. Somewhat more sophisticated procedures can be derived by permitting the model parameters to vary with time but also introduce non-parametric constraints on the parameters (method B2). Stålnacke and Grimvall (1999) have recently proposed a model of the form

$$
L_{i j}=\alpha_{j}+\beta_{i j} q_{i j}+\varepsilon_{i j}, \quad i=1,2, \ldots, n, \quad j=1,2, \ldots, m,
$$

where the slope and intercept parameters are estimated by minimizing

$$
S(\alpha, \beta)=\sum_{i, j}\left(L_{i j}-\alpha_{j}-\beta_{i j} q_{i j}\right)^{2}+\lambda_{1} \sum_{i, j}\left(\beta_{i j}-\frac{\beta_{i+1, j}+\beta_{i-1, j}}{2}\right)^{2}+\lambda_{2} \sum_{i, j}\left(\beta_{i j}-\frac{\beta_{i, j+1}+\beta_{i, j-1}}{2}\right)^{2}
$$

and $\lambda_{1}$ and $\lambda_{2}$ are 'penalty factors' for nonlinear interannual and interseasonal variation in the slope parameters $\beta_{i j}$. Using the same technique, it is also possible to handle models in which the slope parameters are fixed for each season and the intercepts are time-varying. In both cases, the two penalty factors ensure that the model parameters vary slowly with year and season. General features of the roughness penalty approach to linear models with time-dependent parameters have been described in several articles (e.g. Silverman, 1985; Engle et al., 1986) and a textbook written by Green and Silverman (1994).

Suitable levels of the penalty factors $\lambda_{1}$ and $\lambda_{2}$ can be established by undertaking a crossvalidation study of relationships between $L_{i j}$ and $q_{i j}$. Flow-normalization is then accomplished by employing the formula

$$
\hat{L}_{i j}=L_{i j}-\left(q_{i j}-\bar{q}_{. j}\right) \hat{\beta}_{i j},
$$

where $\hat{\beta}_{i j}$ depicts parameter estimates obtained by using the roughness penalty approach described above

\section{Data base}

The present study was based on time series of water quality and water discharge data from 10 catchments in Norway's national monitoring programme for agricultural runoff and from 
selected agriculturally dominated catchments included in the Swedish national monitoring programme for lakes and streams.

In Norway, flow-proportional sampling is employed to collect weekly or fortnightly water samples. Water discharge is recorded continuously. Monthly nutrient exports are calculated by summing up daily loads. The Norwegian monitoring program consists of 10 major catchments ranging from 50 to 2000 ha. In this paper, we consider three catchments, the Kolstadbekken catchment $\left(3.1 \mathrm{~km}^{2}, 68 \%\right.$ agricultural land), the Mørdre catchment $\left(6.8 \mathrm{~km}^{2}, 65 \%\right.$ agricultural land), and the Hotran catchment (19.4 $\mathrm{km}^{2}, 80 \%$ agricultural land).

The data from the Swedish catchments consisted of nitrogen concentrations in grab samples collected once a month and monthly average water discharge data recorded at gauging stations. Linear interpolation was used to estimate daily concentrations of total-N. That is, points representing observed values were connected with straight lines to produce complete series of daily values; and these daily concentration records were aggregated to estimate monthly mean concentrations. Monthly nitrogen exports were calculated as products of monthly mean concentrations and monthly water discharge values. Analysis of the Rönneå catchment (952

$\mathrm{km}^{2}$ ), exemplifies the results from the Swedish catchments. Further description of the sampling sites can be found in Bechmann et al. (1999) and Stålnacke et al. (1999).

\section{Results}

Case 1, method A2.

The upper scatter chart in Figure 1 illustrates that monthly nutrient loads are almost linearly related to the water discharge. In this case, method A2 (formula 1 , slope $\beta=9.2$ and $\bar{q}_{\text {.. }}=83$ ) may provide an acceptable flow-normalization. However, closer examination of the data set revealed that the load at a given discharge tended to increase over the 12-year study period (Figure 1, bottom). Hence, there is a need of flow-normalization methods that can accommodate gradual changes in the relationship between load and water discharge. 

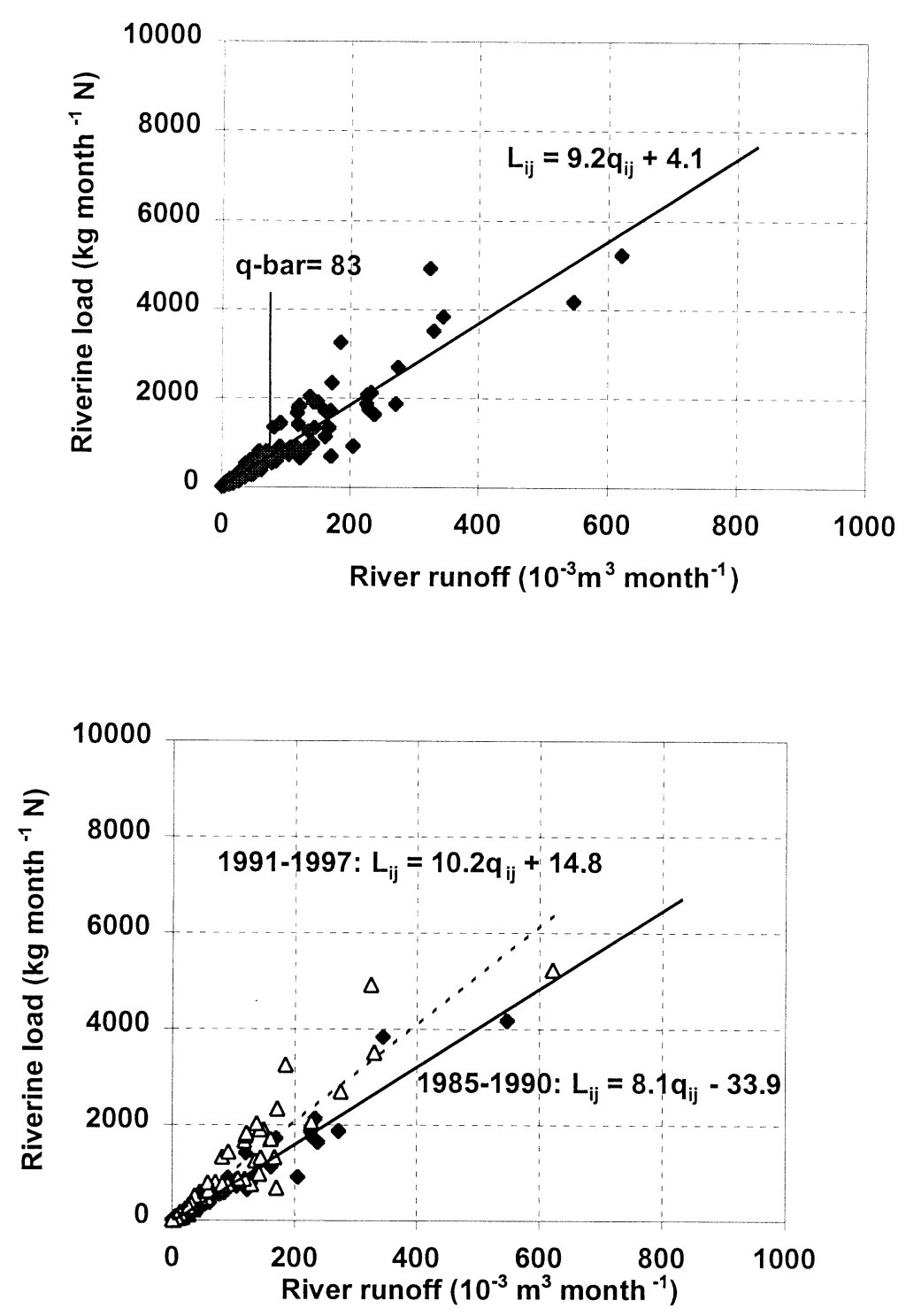

Figure 1. Scatter charts of the load of nitrogen vs. river runoff in the agriculturally dominated Kolstadbekken stream in southern Norway $\left(3.1 \mathrm{~km}^{2}, 68 \%\right.$ agricultural land) 1985-1997.

Cases 2 and 3, method B2.

Analysis of a variety of data sets on nutrient loads and water discharge in agriculturally dominated catchments in Norway and Sweden showed that the type of load-discharge relationships found in the Kolstadbekken stream are prevalent in Scandinavia. Furthermore, the flow-normalized annual loads obtained by employing method B2 invariably formed smooth curves (Figures 2 and 3). 


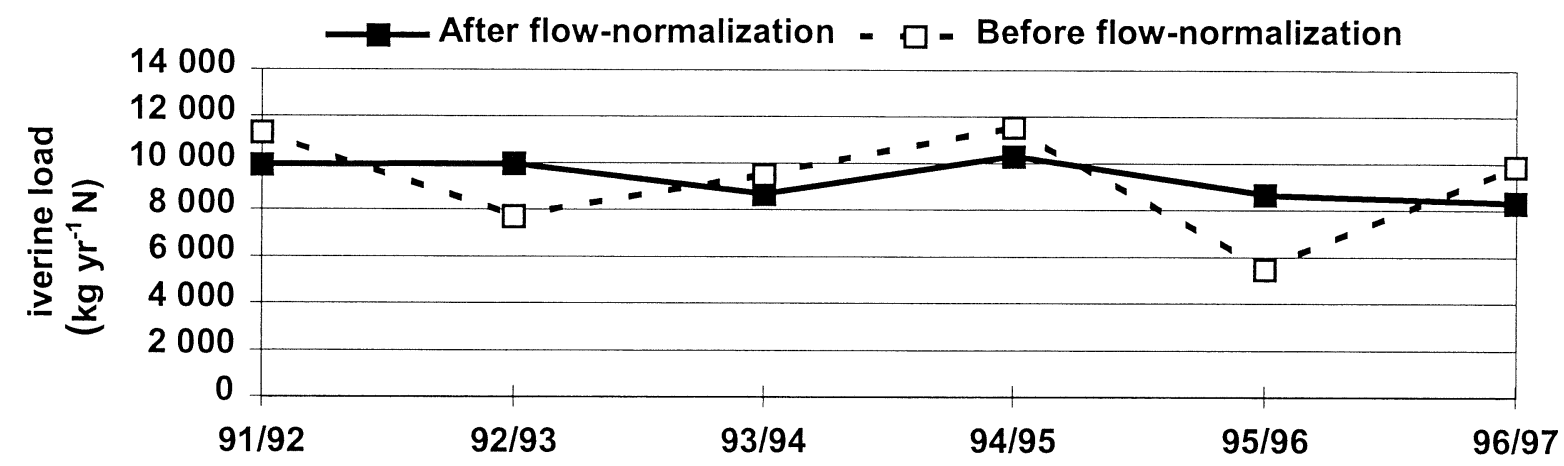

Figure 2. Annual nitrogen loads in the agriculturally dominated catchment of the Mørdre stream in southern Norway (drainage area $6.8 \mathrm{~km}^{2}$ ). The two curves depict transported amounts before and after hydrological normalization according to method B2. The time period studied comprised the agrohydrological years 1991/92-1996/97.

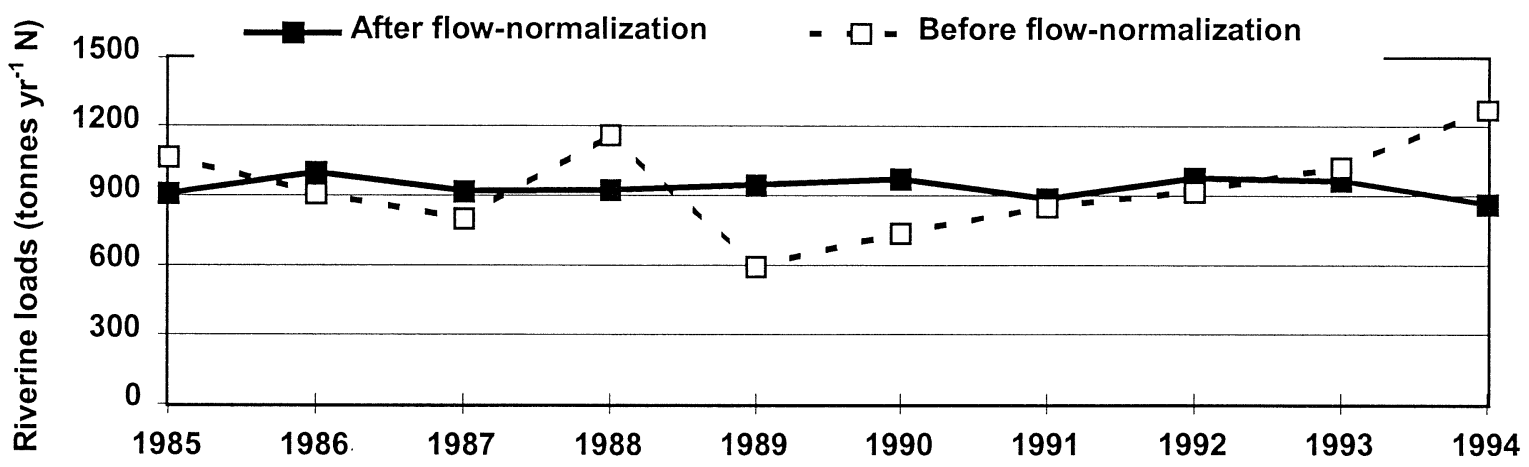

Figure 3. Annual nitrogen loads in the agriculturally dominated catchment of the Rönnea stream in southern Sweden (drainage area $952 \mathrm{~km}^{2}$ ). The two curves depict transported amounts before and after hydrological normalization according to method B2. The study period was 1985-1994.

Case 4, methods $A 1, A 2, A 3, B 1$ and $B 2$

When different flow-normalization techniques were applied to the same data set it was noted that all the methods (A1, A2, A3, B1 and B2) produced relatively smooth curves of annual nutrient loads, i.e. a substantial part of the interannual variability in loads could be explained by fluctuations in discharge. 


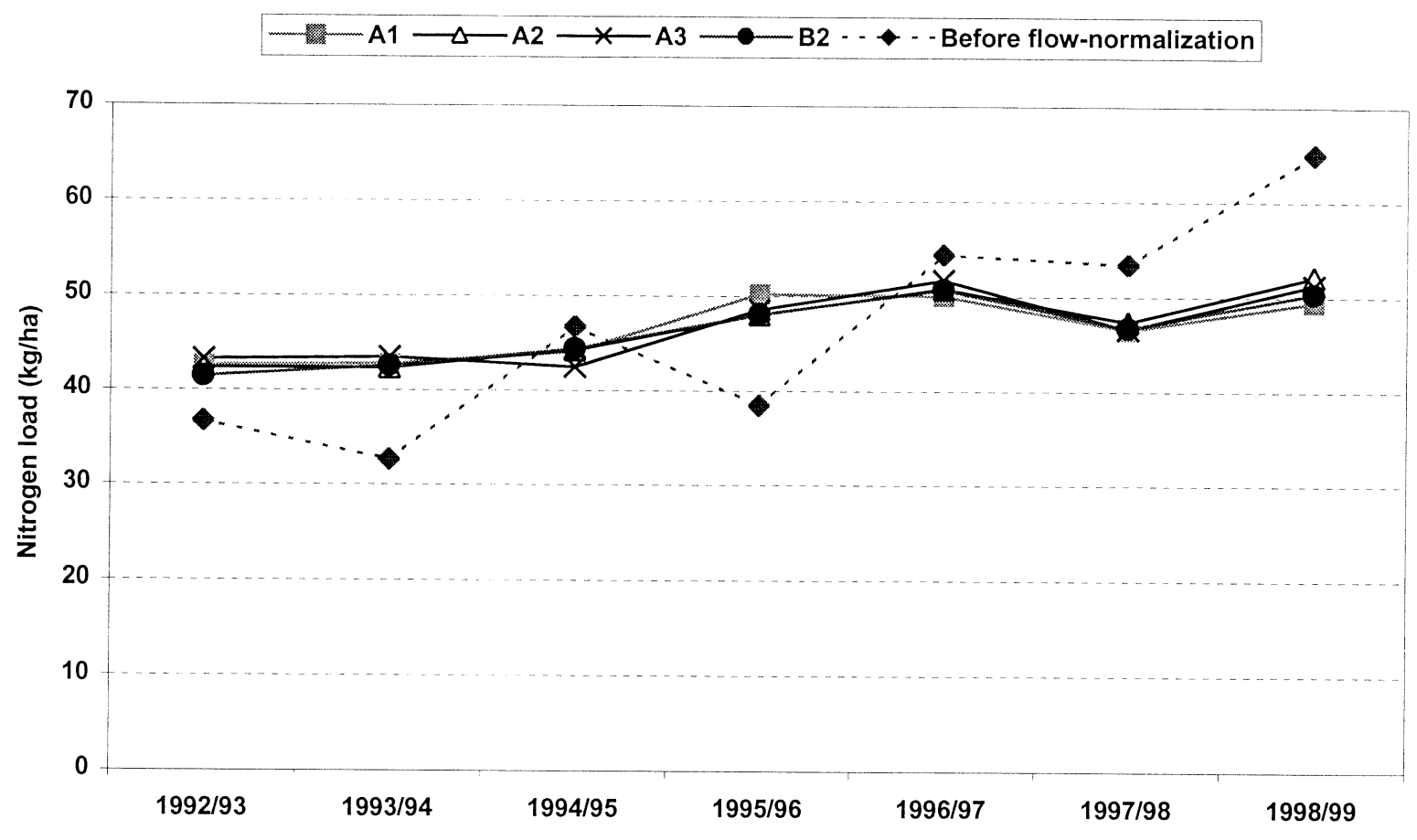

Figure 4. Performance of different flow-normalization techniques in the agriculturally dominated catchment of the Hotran stream in mid-Norway. The curves depict transported amounts of nitrogen before and after hydrological normalization using four methods described in this article (A1, A2, A3, and B2). The study period comprised the agrohydrological years 1992/93-1998/99.

Closer examination of the different flow-normalization techniques revealed that the results obtained by employing the two simplest techniques (A1 and A2) differed somewhat from those of the other techniques (Fig. 4). In addition, it was noted that method B2 generally removed a larger fraction of the interannual variation in nutrient loads than did any of the other methods.

Case 5, methods $A 1$ and $A 2$

Although the methods A1 and A2 produced similar results for all empirical data sets, there could be situations when the different methods produce substantially different flow-normalized loads. For example, Figure 5b shows one such case when the difference between methods A1 and A2 is particularly large. The underlying data shows that there is a good relationship between the concentration and runoff (Fig. 5a); this, in combination with the pronounced trend in runoff (and concentration), will cause a spurious upward trend in the normalized loads if method A1 is employed. In contrast, method A2 uses load and runoff relationships that remove the runoffinduced trend more efficiently than A1 (Fig. 5b). 
$A$

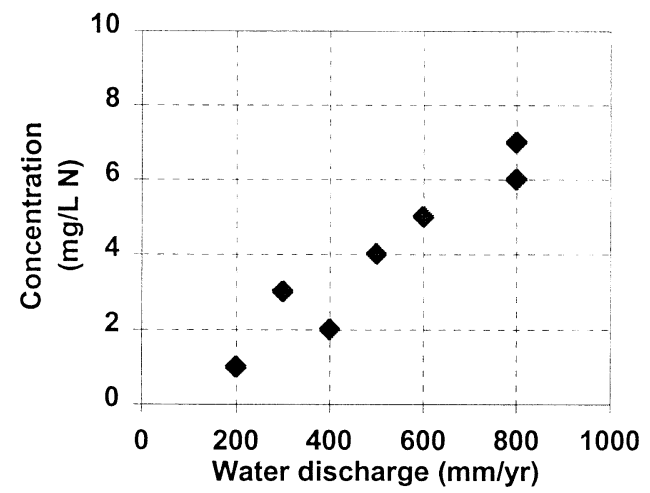

$B$

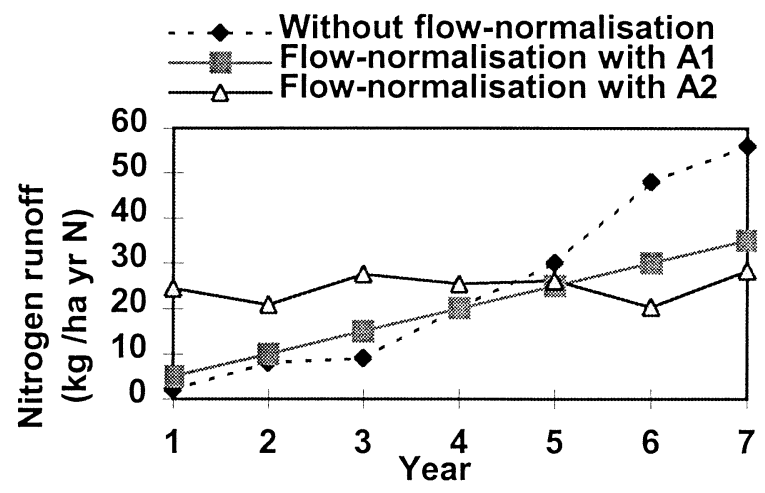

Figure 5. (A) Scatter chart of the relationship between annual mean nitrogen concentration and annual water discharge. Data are hypothetical. (B) Annual riverine loads of nitrogen before and after flow-normalization according to methods A1 and A2, respectively.

Case 6, method B2

Flow-normalization of phosphorus exports was more problematic. Specific hydrological events tended to introduce non-linearities, and in some cases flow-normalization removed only a small fraction of the total interannual variation in phosphorus loads (Fig. 6, upper). In other cases, we were able to remove a larger fraction of the interannual variation (Figure 6, lower). 

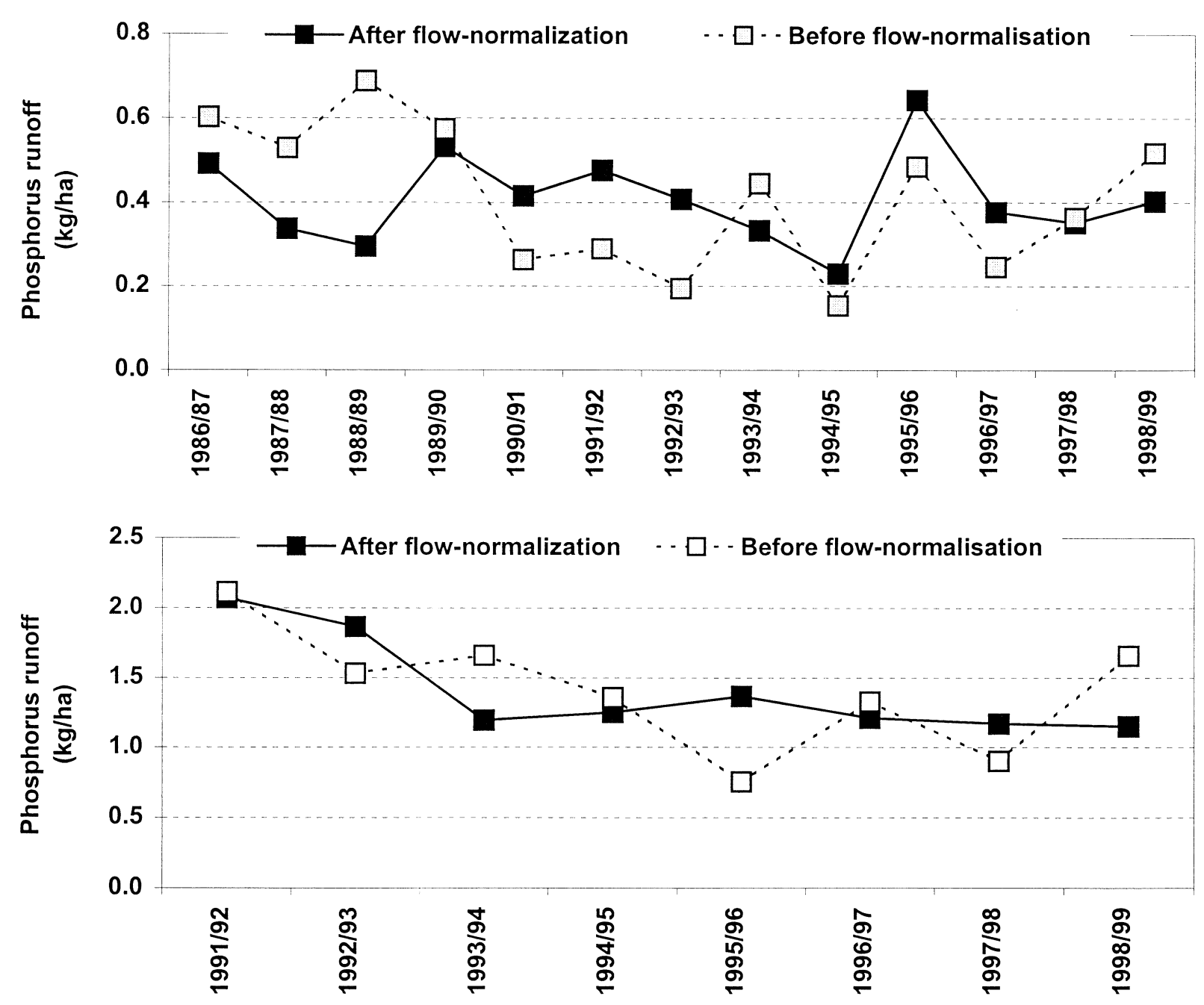

Figure 6. Annual phosphorus runoff in the agriculturally dominated catchments of the Kolstadbekken stream (drainage area $3.1 \mathrm{~km}^{2}$ ) and the Mørdre stream (drainage area $6.8 \mathrm{~km}^{2}$ ), in southern Norway. The two curves depict transported amounts before and after hydrological normalization according to method B2.

\section{Discussion}

Flow-normalization according to method A1 may occasionally remove a substantial fraction of the temporal variation in nutrient loads. However, in general, this method is too simplistic. A1 does not take into account how the nutrient concentration varies with season or water discharge. This flaw of method A1 is also shared by method A2, which often produces similar normalized values. Method A3 is substantially more flexible, because it accounts for both the seasonal variation in concentration and the seasonal distribution of the water discharge. Therefore, A3 
can be regarded as a standard method when the load-discharge relationships remain fairly constant over the whole study period.

When significant trends are present, and load-discharge relationships gradually change over time (which is normal for emissions from agricultural sources), methods B1 and B2 would be the first choice. Recent studies have demonstrated that the semi-parametric B2-method performs well for large or moderately large rivers (Stålnacke\& Grimvall, 1999; Stålnacke et al., 1999). Our study shows that B2 can also be applied to nitrogen exports from relatively small, agriculturally dominated catchments. When applied to data regarding phosphorus (and suspended solids), the performance of the two methods was found to be less satisfactory (Fig. 6). This limitation does not imply that the method is incorrect. To be more precise, it is a wellknown fact that the loss-processes from agricultural soils to waters are fundamentally different for nitrogen than for phosphorus. Nitrogen is lost to waters mostly in a soluble phase, while phosphorus (at least in the Nordic countries) is heavily bound to particles and transported by soil-erosion processes. Thus, phosphorus losses are extremely variable over time, with large peaks at hydrological events. Rainfall episodes makes it difficult to natural variability and the variability related to agricultural factors. Nevertheless, it is our experience that we in many case studies were able to remove a large fraction of the variability in the monitored phosphorus load (e.g. Stålnacke, 1999; Bechmann et al., 1999).

Statistical significance tests of the hydrologically normalized time series were outside the scope of this study. However, it is doubtful that the parametric or semiparametric flownormalization techniques would influence the properties of statistical significance tests like the classical and robust Mann-Kendall test (Kendall, 1975) or the seasonal Mann-Kendall test with correction for serial dependence (Hirsch \& Slack, 1984). This study clearly shows that the hydrologically normalized time series help the interpretation of trends in observed nutrient runoff data from agricultural catchments.

\section{Summary}

- Hydrological normalization of nitrogen exports from agricultural catchments can facilitate interpretation of temporal changes in observed export data, whereas flow-normalization of phosphorus exports is problematic.

- A newly developed, flexible semiparametric approach is proposed for the hydrological normalization.

\section{Acknowledgements}

The Research Council of Norway financially supported this study. The authors are grateful to the Norwegian Monitoring Program for Agricultural Runoff (JOV $\AA$ ) and the Swedish University of Agricultural Sciences for providing stream water quality and water discharge data. We are also grateful to Dr William Warner for revising the language. 


\section{References}

Bechmann, M., Eggestad, H.O., Våje, P.I., Stålnacke, P. and Vagstad, N. 1999. Jordsmonnovervåking i Norge. Erosjon och næringstoffavrenning -resultater til og med 1998/99. Jordforsk Technical Report No. 77/99. (In Norwegian).

Behrendt, H. 1997. Detection of anthropogenic trends in time series of riverine load using windows of discharge and long-term means. ICES-Report cm1997/env:11 of the ICES/OSPAR workshop on the identification of statistical methods for temporal trends, Annex 5, 20-29.

Engle, R.F., Grangler, C.W.J., Rice, J.A. and Weiss, A. 1986. Semiparametric estimates of the relation between weather and electricity sales. Journal of American Statistical Association 81: 310-320.

Esterby, S. 1996. Review of methods for the detection and estimation of trends with emphasis on water quality applications. Hydrological Processes 10: 127-149.

Green, P.J. and Silverman, B.W. 1994. Nonparametric regression and generalized linear models a roughness penalty approach. Chapman and Hill, London.

Hansen, S., Jensen, H.E., Nielsen, N.E. and Svendsen, H. 1991. Simulation of nitrogen dynamics and biomass production in winter wheat using the Danish simulation model DAISY. Fertilizer Research 27: 245-259.

Helsel, D.R. and Hirsch, R.M. 1992. Statistical Methods in Water Resources. Elsevier.

Hirsch, R.M. and Slack, J.R. 1984. A nonparametric trend test for seasonal data with serial dependence. Water Resources Research 20: 727-732.

Hirsch, R.M., Slack, J.R. and Smith, R.A. 1982. Techniques of trend analysis for monthly water quality data. Water Resources Research 18: 107-121.

Johnsson, H., Bergström, L., Jansson, P.E. and Paustian, K. 1987. Simulated nitrogen dynamics and losses in a layered agricultural soil. Agric. Ecosystems Environ. 18: 333-356.

Kendall, M.G. 1975. Rank correlation methods. $4^{\text {th }}$ edition, Charles Griffin, London.

Loftis, J.C., Taylor, C.H. and Chapman, P.L. 1991. Multivariate tests for trend in water quality. Water Resources Research 27: 1419-1429.

Silverman, B.-W. 1985. Some aspects of the spline smooothing approach to nonparametric regression curve fitting. Journal of the Royal Statistical Society B 47: 1-52.

Stålnacke, P. 1999. Time series analysis of the nutrient loads in two medium-sized agricultural streams in Norway. Manuscript.

Stålnacke, P. and Grimvall, A. 1999. Semiparametric approaches to flow-normalisation and source apportionment of substance transports in rivers. Environmetrics (accepted).

Stålnacke, P., Grimvall, A., Sundblad, K., and Wilander, A. 1999. Trends in nitrogen transport in Swedish rivers. Environmental Monitoring and Assessment 59: 47-72.

Young, R.A., Onstad, C.A., Bosch, D.D. and Anderson, W.P. 1989. AGNPS: a nonpoint source pollution model for evaluating agricultural watersheds. J. Soil and Water Cons. 44: 168-173. 